\title{
Help Us Chart a Course for Canada's Nursing Professions
}

\author{
Mary Ellen Jeans, RN, PhD \\ Health Policy and Research Consultant \\ Adjunct Professor, Faculty of Health Sciences, University of Ottawa \\ Co-chair, Building the Future: A Nursing Human Resource Strategy \\ Ottawa, ON \\ Verna Holgate, LPN \\ Director, Canadian Practical Nurses Association \\ Executive Director, College of Licensed Practical Nurses \\ Co-chair, Building the Future: A Nursing Human Resource Strategy \\ Ottawa, ON
}

\section{Building the Future}

Over the past two years, many nurse leaders have participated in Building the Future, the first national study led and endorsed by Canada's nursing stakeholder groups. The study's overriding goal is to develop an integrated, longterm labour market strategy for Licensed Practical Nurses (LPNs), Registered Nurses (RNs) and Registered Psychiatric Nurses (RPNs).

Through interviews, surveys, focus groups and other strategies, the first phase of the study is focused on gathering current, comprehensive information on all aspects of the nursing labour market. These efforts are helping us paint a current picture of nursing human resources, project long-term requirements, develop options to improve retention and recruitment, and assist in developing an integrated strategy for nursing human resources in Canada.

We will soon be moving into the second phase of the study, which will involve consultations with provincial governments as well as nursing stakeholder groups to achieve consensus on key issues and possible solutions. The input of nursing leaders will be extremely valuable in this phase. Building the Future urges you to participate and to collaborate with our stake- 
holders in developing solutions to ensure an adequate supply of nurses to meet the future healthcare needs of all Canadians.

It's no secret that Canada's healthcare system is in crisis. Nor is it a secret that a key element of that crisis is the national nursing shortage.

Nursing stakeholders have been concerned about the shortage for years. Studies have shown that Canadian nurses have lost jobs through budget cuts and downsizing, that there are not enough students in nursing programs and that many nurses have left the country in search of new opportunities. The nursing workforce is also aging. A study conducted last year by the Canadian Institute of Health Information and the University of Toronto stated that by 2006, Canada would lose anywhere from 30,000 to 65,000 senior nurses through retirement - putting further pressures on a profession that is already stretched thin.

These pressures are taking their toll. Although there are more than 232,000 nurses practising in Canada (CIHI 2001), the shortages and other human resources challenges are eroding nurses' confidence about the value of their work. Nurses report that long hours, heavy workloads and high levels of stress are the norm.

While the issues are well known, hard evidence and data are needed to support them and to make the right recommendations for change. A 1999 report (Dussault et al. 1999) identified serious gaps in the information available on the nursing sector - in particular, a lack of current, consistent data on Licensed Practical Nurses (LPNs), Registered
Nurses (RNs) and Registered Psychiatric Nurses (RPNs). Building the Future was created to address these needs.

Launched in 2002, Building the Future is the first national study led and endorsed by the country's nursing stakeholder groups, including professional nursing organizations, unions, employers, researchers, educators, physicians, and federal, provincial and territorial governments. Funded by the nursing community and the Government of Canada (through the Human Resources and Skills Development Canada Sectoral Partnership Initiative), the study's overriding goal is to develop an integrated, long-term labour market strategy for LPNs, RNs and RPNs. While there have been numerous studies of the national nursing sector, this is the first to look at all three professions in such depth. The results will have significant implications for all nurses, including nurse leaders.

Scheduled to conclude later this year, phase one of the study comprises indepth research to gather current, detailed information on all aspects of the nursing labour market, including such issues as career paths and mobility, attrition rates, stress and workload. Phase two will involve consultations with stakeholder groups to achieve consensus on the key issues and the strategies to resolve them.

Taken together, these collaborative efforts will help paint a current picture of nursing human resources, project long-term requirements, develop options to improve retention and recruitment and assist in developing an integrated strategy for nursing human resources in Canada. 
This approach will also provide the foundation for national and international efforts to address the shortages that afflict the nursing labour market around the world. As the study research team identified in its report on the international nursing labour market (Baumann et al. 2004a), Canada and other countries must cooperate in planning and research to help recreate nursing capacity globally.

The Nursing Effectiveness, Utilization and Outcomes Research Unit, a collaborative project of the University of Toronto Faculty of Nursing and the McMaster University School of Nursing, are conducting phase one research activities. Led by Dr. Linda O'Brien-Pallas at the University of Toronto, the team also includes researchers from McMaster University, Dalhousie University and the University of Ontario Institute of Technology.

The team's achievements so far include conducting focus groups with student nurses and union activists across the country; surveying nearly 40,000 randomly selected LPNs, RNs and RPNs across Canada about their workplaces, their health, patients, job satisfaction and career paths; surveying senior nurse managers to learn about such issues as recruitment and retention strategies, clinical teaching practices and managerial decision-making; surveying Canada's nursing schools to determine their current and future training capacity; and conducting a series of interviews with 50 CEOs of organizations that employ nurses.

As part of this research, Building the Future is also releasing a series of reports. The International Nursing Labour Market (Baumann et al. 2004a) points out that shortages and supply problems characterize the worldwide nursing labour market. The report calls for national and international collaboration, specifically in developing national and international plans to recreate nursing capacity through meaningful recruitment and retention policies; and the creation of an international nursing labour force database, as well as a nationally and provincially integrated Canadian database, for healthcare workforce planning.

The research team released another report, Mobility of Nurses in Canada (Baumann et al. 2004b). It examines the interjurisdictional migration of the three regulated nursing professions over the past decade, based on a comprehensive review of published literature, grey literature, statistical data and data from regulatory bodies. Several broad patterns of mobility emerge:

- the movement of nurses in Canada resembles that of the general population, with an east-to-west flow of migrants;

- for RNs and LPNs, Atlantic Canada and Western Canada form regional markets within which there is mutual exchange of nursing personnel;

- RPNs migrate among the provinces of Western Canada, where they are regulated; and

- interprovincial mobility increased between 1990 and 1997, with Alberta, British Columbia, Nova Scotia and Ontario having the highest immigration rates. 
Despite such patterns, the report emphasizes the lack of consistent, reliable data and makes it clear that Canada does not have the systems in place to follow nurses' career paths accurately. The research team calls for corrective measures, including coordinated national collection of accurate information on all three regulated nursing professions and adoption of a unique, lifetime identifier that would offer a reliable tool for tracking nurses throughout their careers and support a database for workforce projections and planning.

Further reports scheduled for release this year include a review of nursing education and an assessment of capacity, analysis of how changing healthcare needs contribute to changing patterns of nursing care delivery, analysis and review of immigration and emigration trends and other topics.

Early in 2005, Building the Future will conclude the first phase of its work by publishing a final report that integrates the key challenges and recommendations of all aspects of its research. The study will then launch phase two: in-depth consultations with nursing stakeholders to achieve consensus on the issues and develop viable strategies and solutions. While the details of the consultation plan are not yet final, the overall approach is to engage in workshop, panel and other discussions across Canada.

One way to create change successfully is to link the issues with those identified in other studies and commissions on the healthcare sector. Another is to consider how our needs mesh with the priorities of the federal and provincial governments.
In fact, before this study's steering committee approaches other stakeholder groups next year, consultations with all provincial and territorial jurisdictions will be conducted to obtain their input on the research findings and their commitment to being involved in strategy development.

No change can be made in isolation. As we move forward, we will continue to keep stakeholders up to date on our progress. We will also continue to solicit input from our stakeholders so that all players are represented fairly and accurately. Most important, the Building the Future stakeholders are committed to cooperating beyond the life of the study to ensure that resulting options are implemented.

As leaders in the nursing sector, your perspectives are especially valuable, and we appreciate the contributions many of you have already made to the study. We urge you to participate in the next phase, as nursing stakeholders collaborate on strategies to ensure an adequate supply of nurses to meet the future healthcare needs of all Canadians.

For more information about Building the Future, or to contact us, please visit our website at www.buildingthe future.ca.

\section{References}

Baumann, A., J. Blythe, C. Kolotylo and J. Underwood. 2004a (March). The International Nursing Labour Market. Retrieved July 20, 2004. $<$ http://www.buildingthefuture.ca/e/study/phase1 /reports/11E_Intl_Nursing_Labour_Market.pdf $>$.

Baumann, A., J. Blythe, C. Kolotylo and J. Underwood. 2004b (June). Mobility of Nurses in Canada. Retrieved July 20, 2004. <http://www. buildingthefuture.ca/e/study/phase1/reports/ Step12_ENG_10.pdf $>$. 
Canadian Institute for Health Information. 2001. Canada's Health Care Providers, 2001. Retrieved July 22, 2004. <http://secure.cihi.ca/cihiweb/ dispPage.jsp?cw_page=AR_35_E $>$.

Dussault, G., M.-A. Fournier, M.S. Zanchetta, S. Kérouac, J.-L. Denis, L. Bojanowski, M. Carpentier and M. Grossman. 1999 (December). "The Nursing Labour Market in Canada: Review of the Literature." Report presented to the Invitational Roundtable of Stakeholders in Nursing. Retrieved July 20, 2004. <http:// www.buildingthefuture.ca//study/background/ en_report.pdf >.

\section{Health Services Access Survey}

Canadians have clearly identified waiting times as their number one barrier in accessing specialized healthcare services, according to the 2003 Health Services Access Survey (HSAS). The survey explored access to three types of specialized care: visits to specialists, non-emergency surgeries and diagnostic tests, as well as access to first contact services.

Between 13\% (non-emergency surgery) and $21 \%$ (specialist visits) of people who accessed specialized care reported that they had encountered difficulties. The majority of those experiencing difficulties reported that the main barrier was that they had to wait too long for care. This finding on waiting times is consistent with previous studies regarding access to healthcare.

(Source: Statistics Canada, June 30, 2004)

\section{Medical Malpractice Lawsuits on a} Rise: True or False

Despite popular belief, the number of medical malpractice lawsuits being filed is actually dropping steadily. According to the Canadian Health Services Research Foundation (CHSRF), a close look at the data shows that while it's true that Canadian malpractice payments have followed an upward trend in recent years and the cost of malpractice protection is much higher than in the past - the number of lawsuits being filed is actually dropping steadily.

According to the association, there was an increase in the number of malpractice lawsuits in the early 1990s (peaking in 1996 when 1,415 lawsuits were filed), but the numbers have dropped since then, to 1,225 in 2002. In other words, the number of lawsuits filed against doctors in Canada has been steadily declining in recent years. Moreover, doctors still win most lawsuits that go to trial $-80 \%$ in 2002 .

(Source: Mythbusters, CHSRF, June 2004)

Find out how to recruit, retain and combine talents with the best of them. Join the HealthcareBoard. Free research, great media and mentoring from the best.

Contact Susan Hale at 4168649667 or shale@longwoods.com

\section{CNIA with the support of Bell Canada is pleased to announce the introduction of its elearning program.}

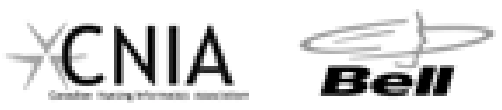

Produced by

Longwoods eLearning

Open your Mind

For more information contact Lina Lopez at Ilopez@longwoods.com 